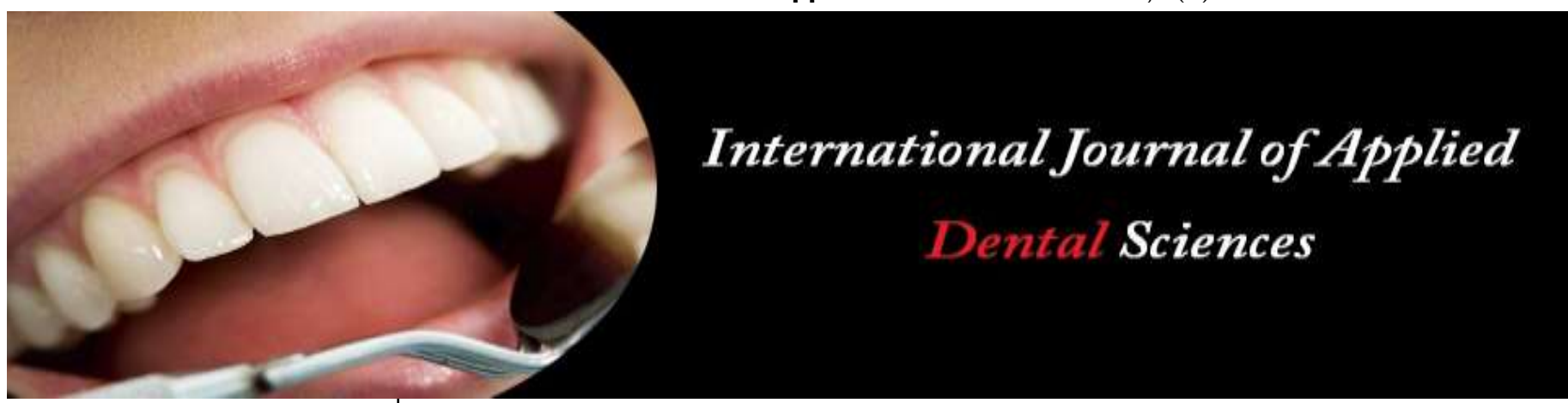

ISSN Print: 2394-7489

ISSN Online: 2394-7497

IJADS 2021; 7(1): 395-397

(C) 2021 IJADS

www.oraljournal.com

Received: 14-12-2020

Accepted: 02-01-2021

Dr. Isha Rastogi

Mds Assistant Professor (AP) in

Mims, Uttar Pradesh, India

\section{Dental state in geriatric patients}

\author{
Dr. Isha Rastogi \\ DOI: https://doi.org/10.22271/oral.2021.v7.i1f.1158
}

\section{Abstract}

Introduction: Prosthodontic care is needed in aging patients as they tend to be most neglected.

Aim: This paper intends to highlight the importance of edentulism and its treatment in elderly population.

Material and Method: Target population was surveyed and studied.

Results: It was seen that geriatric patients require dentures and special prosthesis depending on edentulism and their suitability.

Discussion: It is need of hour that considering higher age and dentate state appropriate measures are taken.

Conclusion: Prosthodontic care for elderly is a critical subject which needs special effort by the fraternity.

Keywords: Dental, geriatric, prosthesis

\section{Introduction}

Edentulism is a challenge in all age groups specially older population. It has been rightly said, "health is wealth". A healthy mouth and replacing missing teeth are necessary for the overall health of an individual.

Weintraub and Buet (1985) used ${ }^{[1]}$ the term 'edentulism' to describe the complete absence of natural teeth, regardless of whether they had been replaced or not. The loss of teeth affects various vital functions as mastication, phonetics, esthetics, dietary intake and nutrition status. It compromises and affects general health ${ }^{[2]}$.

Edentulism is closely associated with socio-economic factors and is more prevalent in poor populations and in women ${ }^{[3,4]}$. We have heard and seen that epidemiological surveys have been conducted in India and abroad on dental caries and periodontal problems but Prosthodontic field has never shown any interest to scholars ${ }^{[5]}$.

Many authors have suggested use of questionnaire to assist diagnostic and prognostic skills. Levin B., Landesman $\mathrm{H} \mathrm{M}$ also ${ }^{[6]}$ suggested that some individuals have difficulty in verbalizing their problems and recommended use of questionnaire which assist patients to reveal their problems. Questionnaire prior to beginning of treatment not only assists the edentulous subject to reveal their problems but also to derive treatment planning addressing awareness of need and expectation of complete denture patients.

\section{AIM and Objectives with clinical relevance}

To conduct clinical survey to assess edentulism in geriatric population and educate them to lead a healthy aging oral life. It is utmost important that elderly patients with multiple dental problems and tooth loss find suitable options and availability for their care.

\section{Material and Methods}

Elderly individuals about 500 above 50 years of which 250 individuals from village were studied and 250 who came to opd in 2 months time were questioned and examined using diagnostic aids. 
In maxillary arch 47and in mandibular 34 with 232 in both arches teeth were missing.

\section{Results}

The patients who gave their consent for study were questioned, examined and then results obtained.

Table 1: In arches Maxillary 47 Mandibular 34 Both 232

\begin{tabular}{|c|c|}
\hline Maxilla & Arch \\
\hline Mandible & 34 \\
\hline Both & 232 \\
\hline
\end{tabular}

Table 2: Problems

\begin{tabular}{|c|c|c|}
\hline & \multicolumn{2}{|c|}{ Problem } \\
\hline Esthetic & & 17 \\
\hline Mastication & & 216 \\
\hline Comfort & & 2 \\
\hline Esth \& Mast. & & 25 \\
\hline Mast.\&Phonetics & & 20 \\
\hline Esth\&Mast\&Phon. & & 33 \\
\hline Cd & & \\
\hline KNOW About & 118 \\
\hline Cd And Rpd/Cpd & & 55 \\
\hline Cd\&Rpd/Cpd\&Fpd & & 50 \\
\hline Cd\&Rpd/Cpd\&Fpd & \&IMPLANT & 31 \\
\hline
\end{tabular}

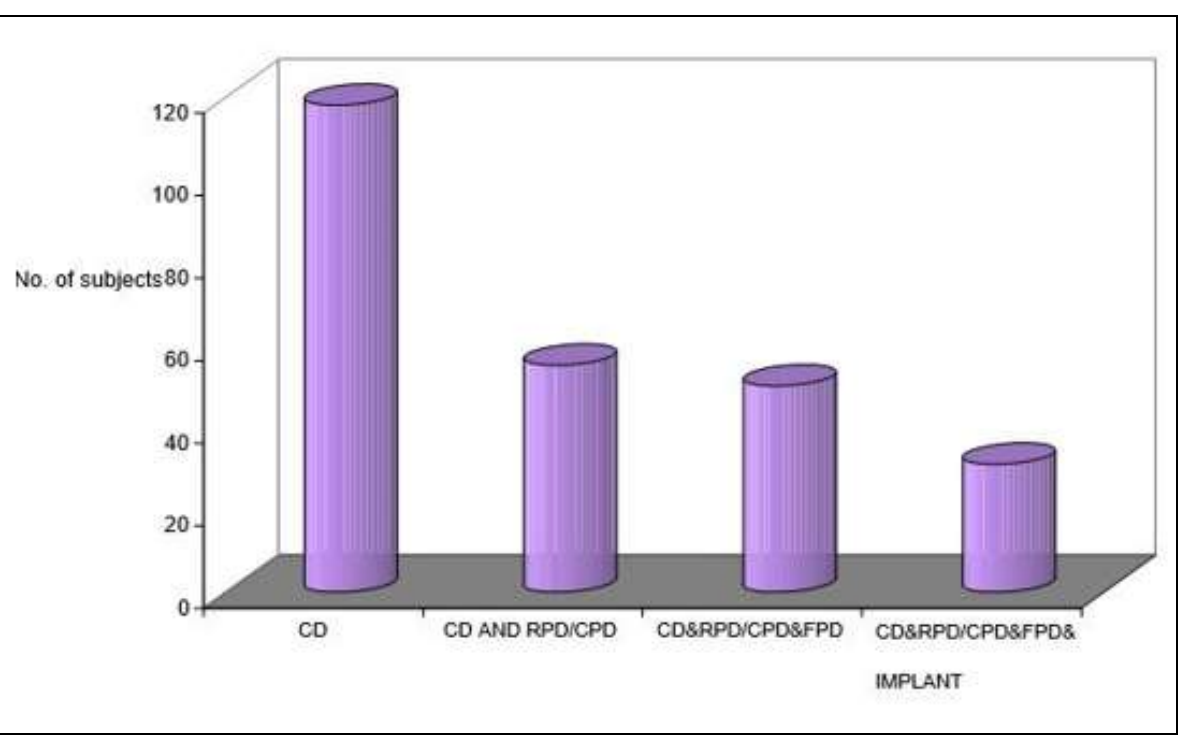

Fig 3: Know about

\section{Discussion}

Older people make extensive use of medical facilities but they seem to underuse dental facilities.

47 subjects reported missing teeth in maxillary arch while 34 subjects had edentulism in mandibular arch.232 subjects had missing teeth in both arches.

The problems suffered due to absence of teeth were that 216 subjects reported it was mastication, 17 subjects gave esthetics as the problem, 2 subjects had discomfort, 25 subjects had combined problems in esthetics and mastication, 20 subjects had problems in mastication and phonetics and 33 subjects gave problems in all 3 esthetics, mastication and phonetics.

Those who knew of Prosthodontics among them 118 knew about complete dentures, 55 subjects had knowledge of complete dentures and removable/cast partial dentures, 50 people knew about complete dentures, removable/cast partial dentures and fixed partial dentures while 31 people had

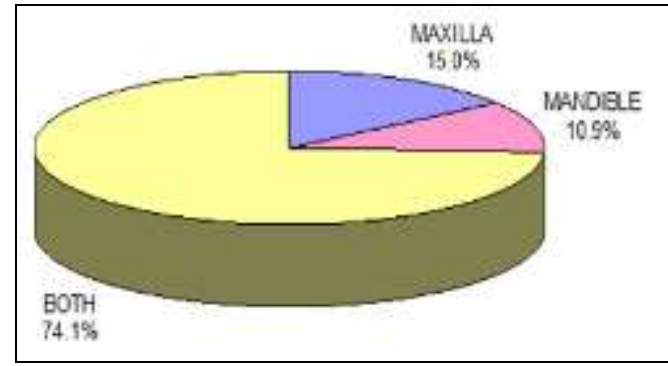

Fig 1: In arches

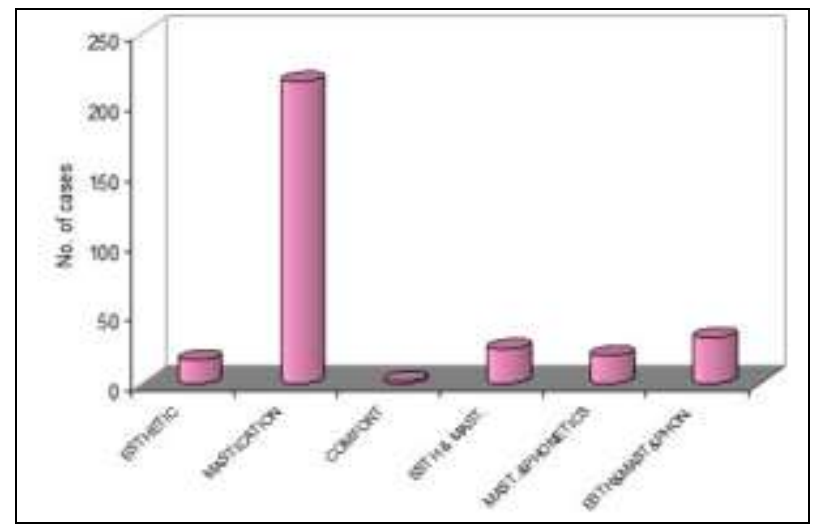

Fig 2: Problems information about complete dentures, removable/cast partial dentures, fixed partial dentures and implants.

The orofacial region is essential to the quality of life and must be reemphasized for the geriatric patient. The extent to which the face and mouth have provided satisfaction of basic biologic and social needs in the past will determine their significance to the quality of life ${ }^{[11]}$.

Edentulism can lead to impairment, functional limitation, physical, psychological and social disability and handicap ${ }^{[7]}$. Other factors contributing to prevalence of complete tooth loss are age, education, access to dental care, dentist/population ratios and insurance coverage ${ }^{[8,9]}$. Progress decline of physical health and vitality and accumulation of losses, deprivations and vicissitudes as age advances give rise to emotional disturbances in a relatively high proportion of elderly ${ }^{[10]}$.

Oral infectious conditions and periodontal disease also increases with age and may be exacerbated by nutritional 
deficiencies ${ }^{[12]}$.

Poor oral health leads to impaired masticatory function. Whether MF plays a role in food selection is still matter of debate, but impaired masticatory function leads to inadequate food choice and therefore alter nutrition intake ${ }^{[13]}$.

The presence of natural teeth and well fitting dentures were associated with higher and more varied nutrition intakes and greater dietary quality ${ }^{[14]}$.

A full upper denture can have an impact on taste and swallowing ability. The hard palate contains taste buds, so taste sensitivity may be reduced when an upper denture covers the hard palate. As a result, swallowing can be poorly coordinated and dentures can become a major contributing factor to death from choking. As adults age, they tend to use more strokes and chew longer, to prepare food for swallowing. Masticatory efficiency in complete denture wearers is approximately $80 \%$ lower than in people with intact natural dentition. The effect of dentures on nutritional status varies greatly among individuals ${ }^{[15]}$ Replacing illfitting dentures with new ones does not necessarily result in significant improvements in dietary intake.

Some people compensate for decline in masticatory ability by choosing processed or cooked foods rather than fresh food and by chewing longer before swallowing. 2. Others may eliminate entire food groups from their diets ${ }^{[16]}$. Dentate adults tend to eat more fruits and vegetables than full-denture wearers. Similarly, exchanging optimal complete dentures for implant-supported dentures, has not resulted in significant improvement in food selection or nutrient intake.

\section{Conclusion}

Treating to needs of geriatric patients is urgently needed. Keeping in mind their problems and the treatment types a lot has to be done in this sometimes neglected area. In this effort was made to assess the elderly and their oral status. They should be encouraged to care for dental status as they care for overall medical state.

\section{References}

1. Weintraub et al. Oral health status in the US:tooth loss and edentulism. J Dent Educ 1985.

2. Suresh S, Swati Sharma. A clinical survey to determine the awareness and preference needs of a complete denture among complete edentulous patients. J Int Oral Health 2010;2(3):65-69.

3. Miller WJ et al. Edentulism and denture use. Health Reports 2005;17(1):55-58 (pubmed google scholar).

4. Bedos et al. The dental care pathway of welfare recipients in Quebec. Social Science and Medicine 2003;57(11):2089-2099. (Pubmed Google scholar).

5. Simhachalam Reddy N. Edentulism-An Epidemiological Survey of Population in Chennai, India. J Orofac Sci, 2010;2(1):14-18.

6. Levin B et al. Journal of Prosthetic Dentistry 1976;35(2):124-130.

7. Locker D. Measuring oral health: A conceptual framework. Community dental health (pubmed Google scholar) 1988;5(1):3-18

8. Elevni HW et al. Socio economic inequalities and oral health in Canada and US. Journal of Dental Research (pubmed Google scholar) 2012;91(9):865-70

9. Brodeur JM et al. Use of dental services and percent of people possessing private dental insurance in Quebec. Journal of Canadian dental Association (pubmed Google scholar). 1996;62(1):83-90.
10. Slater E et al. Comfort aging and mental diseases of aged. Clinical psychiatry $3^{\text {rd }}$ ed, UK: Bailliere Tindall 2001, 535-36.

11. Giddon DB et al. Psychologic aspects of prosthodontic treatment for geriatric patients. JPD 1980;43(4):374-379.

12. Ranganath LM. Nutrition for geriatric denture patient. International Journal of Medical, Dental, Homeopathy and Nursing 2016;1:1-10

13. N'Gom PI, Woda A. Influence of impaired mastication on nutrition. J Prosthet Dent 2002;87:667-73.

14. Marshall, Warren, Hand, Stumbo. Oral health, nutrition intake and dietary quality in the very old. JADA 2002;133:1369-79.

15. Krall E Hayes, Gilbert GH, Duncan P. How dentition status and masticatory function affect nutrition intake. $\mathrm{J}$ Am Dent Assoc 1998;129:1261-9.

16. Greska L, Parraga IM, Clark CA. The dietary adequacy of edentulous older adults. J Prosthet Dent 1995;73:1425 . 